\title{
The follicle-stimulating hormone (FSH) and luteinizing hormone (LH) response to a gonadotropin-releasing hormone analogue test in healthy prepubertal girls aged 10 months to 6 years
}

\author{
Esben T Vestergaard 1,2,3, *, Mia E Schjørring 3,*, Konstantinos Kamperis ${ }^{3}$, \\ Karin Kastberg Petersen ${ }^{4}$, Søren Rittig ${ }^{3}$, Anders Juul ${ }^{5}$, Kurt Kristensen ${ }^{3}$ and \\ Niels H Birkebæk ${ }^{3}$
}

\begin{abstract}
${ }^{1}$ Medical Research Laboratory, Aarhus University, Aarhus, Denmark, ${ }^{2}$ Department of Pediatrics, Randers Regional Hospital, Randers, Denmark, ${ }^{3}$ Pediatrics and Adolescent Medicine, Aarhus University Hospital, Aarhus, Denmark, ${ }^{4}$ Department of Radiology, Aarhus University Hospital, Skejby, Aarhus, Denmark, and ${ }^{5}$ Department of Growth and Reproduction and EDMaRC, Rigshospitalet, University of Copenhagen, Copenhagen, Denmark *(E T Vestergaard and M E Schjørring contributed equally to this work)
\end{abstract}

Correspondence should be addressed to E T Vestergaard Email etv@clin.au.dk

\begin{abstract}
Objective: Premature thelarche and precocious puberty are frequently diagnosed in girls even below 6 years of age and may be difficult to differentiate in the early stages. A GnRH test is often included in the diagnostic work-up, although interpretation of the GnRH test in girls below 6 years of age is challenging, as no reference interval exists for this age group. The objective is to determine the normal FSH and LH response to a GnRH test in healthy prepubertal girls below 6 years of age.

Design and methods: A standardized GnRH test, baseline reproductive hormones, clinical evaluation and bone age were determined in all participants. Forty-eight healthy normal-weight girls aged $3.5 \pm 0.2$ years (range: $0.8-5.9$ years) were included. Serum concentrations of LH and FSH were measured before and $30 \mathrm{~min}$ after the gonadorelin injection.

Results: The 30-min LH responses (mean \pm 2 S.D.) were $5.2 \pm 4.0$ and $2.9 \pm 2.5 \mathrm{IU} / \mathrm{L}$ and the FSH responses were $23.3 \pm 16.2$ and $14.5 \pm 10.3 \mathrm{IU} / \mathrm{L}$ in girls aged $0.8-3.0$ years and 3.0-5.9 years respectively. This corresponds to upper cut-off limits for $\mathrm{LH}$ of $9.2 \mathrm{IU} / \mathrm{L}$ ( $<3$ years) and $5.3 \mathrm{IU} / \mathrm{L}$ ( $3-6$ years). The stimulated LH/FSH ratio was $0.23 \pm 0.19$ (range $0.06-0.43$ ) and did not correlate with age.

Conclusions: We found that LH increases up to $9.2 \mathrm{IU} / \mathrm{L}$ during $\mathrm{GnRH}$ test in healthy normal-weight girls below 3 years of age and that the stimulated LH/FSH ratio did not exceed 0.43 . Our findings have important implications for appropriate diagnosis of central precocious puberty in girls below 6 years of age.

\section{Introduction}

The average age of thelarche (breast development) in healthy girls is $9-10$ years $(1,2)$. Girls who present with thelarche with or without pubarche (pubic hair development) before 8 years of age have traditionally
() 2017 European Society of Endocrinology Printed in Great Britain been evaluated by clinical examination of pubertal signs, growth pattern, bone age, baseline reproductive hormones and a GnRH test (3). Precocious puberty (PP) is most often caused by the activation of the hypothalamic-pituitary- 
gonadal (HPG) axis (central PP, CPP) or less often caused by gonadotropin-independent sex steroid stimulation (3, 4 ), but slowly progressive and non-progressive variants of normal development are also recognized $(5,6)$. Therefore, observation of the tempo of progression for 3-6 months is considered important before any treatment is started.

The gonadotropin-releasing hormone $(\mathrm{GnRH})$ test is the gold standard to detect an activation of the HPG axis $(3,7,8)$. In girls aged below 8 years, a luteinizing hormone (LH) response above approximately $5 \mathrm{IU} / \mathrm{L}$ or a LH/FSH ratio above 1 are often used to discriminate between a pathological and a normal physiological LH response $(7,9,10)$. However, in girls aged below 6 years, the gonadotropin response to the GnRH test has not been investigated in healthy girls, and thus, no valid reference interval exists for this test. Such reference interval to the GnRH test in this age group is often warranted because girls with advanced breast development in this age group are frequently referred for diagnostic work-up and treatment $(11,12,13)$.

The aim of this study was to evaluate the FSH and LH response to a GnRH test in prepubertal girls aged 10 months to 6 years.

\section{Patients and methods}

\section{Subjects}

Forty-eight prepubertal and healthy girls below 6 years of age were recruited from the greater Aarhus area after advertising on the Internet (http://www.forsoegsperson. dk), bulletin boards in day care centers and at the University Hospital in Aarhus. Girls undergoing routine scintigraphy screening 4-6 months after an upper urinary tract infection, needing an intravenous access for this procedure, were also asked to participate. None of the girls presented with or had a history of breast buds, pubic or axillary hair, acne or vaginal bleeding. One girl aged 1.8 years was adopted from Ethiopia.

\section{Study protocol}

All subjects were examined on one occasion. The studies were conducted at the Department of Pediatrics, Aarhus University Hospital, and performed between 08:00 and 16:00 h in a quiet, thermoneutral indoor environment. Height, weight and pubertal stage according to Tanner (14) were recorded, and bone age was determined from an X-ray of left hand and wrist by BoneXpert software (Visiana Aps Holte, Denmark) (15) according to Greulich and Pyle (16). Body surface area was estimated according to the Haycock formula (17).

\section{GnRH test procedure}

After topical administration of a local anesthetic agent (Emla (lidocaine and prilocaine); AstraZeneca), an intravenous (IV) cannula was inserted into the antecubital region for blood sampling and gonadorelin injection. One blood sample was drawn for baseline measurement of serum levels of estradiol, inhibin B, anti-Mullerian hormone (AMH), sex hormone-binding globulin (SHBG), LH (LHO), FSH (FSHO) and thyroid-stimulating hormone (TSH). Subsequently, Gonadorelin (PubChem CID 638793, Sanofi-Aventis; Relefact $0.1 \mathrm{mg} / \mathrm{mL}$, Sanofi-Aventis Hørsholm, Denmark) $0.1 \mathrm{mg} / \mathrm{m}^{2}$ body surface area (max $0.1 \mathrm{mg}$ ) was injected as an IV bolus. After $30 \mathrm{~min}$, a second blood sample was drawn for the measurement of serum levels of LH and FSH (9).

\section{Biochemical analyses}

Blood samples were centrifuged at $1600 \mathrm{~g}$ for $10 \mathrm{~min}$ at $4^{\circ} \mathrm{C}$. Serum was then transferred to tubes and stored at $-80^{\circ} \mathrm{C}$ until analysis.

Serum LH, FSH, TSH and SHBG were determined using Cobas e601 platform (Roche Diagnostics). The intermediary coefficients of variations (CVs) were 2.3\% (LH), 2.5\% (FSH), $1.8-1.9 \%$ (TSH) and $2.1-2.9 \%$ (SHBG) respectively. Detection limits were $0.1 \mathrm{IU} / \mathrm{L}$ (LH), $0.1 \mathrm{IU} / \mathrm{L}$ (FSH), $0.005 \mathrm{IU} / \mathrm{L}$ (TSH) and $0.35 \mathrm{nmol} / \mathrm{L}$ (SHBG) respectively. $\mathrm{LH}$, FSH, estradiol and SHBG analyses are validated through the external quality program UK NEQAS. TSH analyses are validated through the external quality program Lab Quality.

Inhibin B concentrations were determined by a twosided enzyme-linked immunosorbent assay (Inhibin B Gen II ELISA; Beckman Coulter, Brea, CA, USA). Detection limit was $3 \mathrm{pg} / \mathrm{mL}$, intra-assay and interassay CV\% were $2.2 \%$ (at $43 \mathrm{pg} / \mathrm{mL}$ ) and $10.3 \%$ (at $36 \mathrm{pg} / \mathrm{mL}$ ) respectively. AMH concentrations were determined by a chemiluminescent immunoassay (Access AMH, Access 2 Immunoassay System, Beckman Coulter). Detection limit was $0.14 \mathrm{pmol} / \mathrm{L}$, intra-assay and interassay $\mathrm{CV} \%$ were $1.8 \%$ (at $19 \mathrm{pmol} / \mathrm{L}$ ) and $1.8 \%$ (at $7 \mathrm{pmol} / \mathrm{L}$ ) respectively. Inhibin $\mathrm{B}$ and $\mathrm{AMH}$ assays are validated in our accredited lab (www.danak.dk). Measurements of serum estradiol were based on a liquid extraction step followed by liquid chromatography-tandem mass spectrometry (LC/MS/ MS). No derivatization reagent was used to enhance the signal. The samples were extracted on a Novum simplified extraction plate using a 50:50 heptane:ethyl acetate 
mixture. After evaporation of the extraction solvents, the samples were reconstituted in $200 \mu \mathrm{L}$ of mobile phase. $50 \mu \mathrm{L}$ was injected on Phenomenex EVO column on a Shimadzu Nexera HPLC system coupled to a Sciex 6500 QTRAP mass spectrometer using negative-mode electrospray ionization. The lower limit of quantitation (LoQ) was $15 \mathrm{pmol} / \mathrm{L}$. The coefficient of variation was $\leq 7.5 \%$ and $13.8 \%$ at concentrations of $100 \mathrm{pmol} / \mathrm{L}$ and above and of $24.3 \mathrm{pmol} / \mathrm{L}$ respectively.

\section{Statistical analyses}

Serum LH, FSH, the LH/FSH ratio and SHBG were normally distributed. TSH, inhibin B and AMH were non-normally distributed. Normally distributed data are reported as mean \pm 2 standard deviations (s.D.) and mean \pm S.E.M. (age, bone age, height, weight, BMI and SHBG), whereas nonnormally distributed data are reported as median and 25-75\% interquartile range. Correlations were tested with the Pearson product-moment correlation test and the Spearman rank order correlation test, and a $P$ value $<0.05$ was considered statistically significant. Statistical analyses were performed using SigmaPlot for Windows, version 11.0 (Systat Software, Inc.).

\section{Ethical considerations}

The study was conducted in accordance with the Helsinki Declaration and the participants' parents or legal representatives gave their oral and written informed consent for their daughters to participate. The Local Ethics Committee and the Danish Medicines Agency approved the study protocol, and the protocol was registered at Clinicaltrials.gov NCT01944488 before the onset of enrolment.

\section{Results}

Forty-eight healthy normal-weight girls with a bone age in accordance with chronological age in Tanner stage I and aged $3.5 \pm 0.2$ years (range 10 months to 5 years and 11 months) were enrolled in this study. Heights, weights, BMI, BMI Z-scores and bone ages are shown in Table 1 . All subjects were euthyroid with TSH levels of 3.1 (2.1-4.0) IU/L.

Serum levels of estradiol were below detection limit in all participants. AMH concentrations were 15.5 (7.922.5) pmol/L, inhibin B concentrations were 13.0 (8.021.5) $\mathrm{pg} / \mathrm{mL}$ and serum SHBG levels were $146.7 \pm 5.6 \mathrm{nmol} / \mathrm{L}$. Inhibin B correlated inversely with age $(r=-0.38, P<0.001)$, whereas AMH and SHBG did not vary with age.

\section{Baseline and stimulated LH and FSH concentrations}

Baseline LH was below detection limit in all except three girls (aged 3.68, 0.80 and 2.08 years), in whom LH concentrations were $0.17,1.68$ and $0.20 \mathrm{IU} / \mathrm{L}$ respectively.

Table 1 The hormonal response to a GnRH test. The table shows the median, minimal and maximal gonadotropin-stimulated LH and FSH response and the corresponding LH/FSH ratio for the subjects subdivided into six groups according to age.

\begin{tabular}{|c|c|c|c|c|c|c|}
\hline & \multicolumn{6}{|c|}{ Age group, years } \\
\hline & $0-1$ & $1-2$ & $2-3$ & $3-4$ & $4-5$ & $5-6$ \\
\hline$n$ & 3 & 9 & 9 & 7 & 10 & 10 \\
\hline Age (years) & $0.93 \pm 0.08$ & $1.57 \pm 0.10$ & $2.55 \pm 0.11$ & $3.54 \pm 0.06$ & $4.59 \pm 0.10$ & $5.69 \pm 0.07$ \\
\hline Bone age (years) & $0.94 \pm 0.06$ & $1.67 \pm 0.17$ & $2.48 \pm 0.15$ & $3.15 \pm 0.21$ & $4.27 \pm 0.27$ & $5.17 \pm 0.31$ \\
\hline Height $(\mathrm{cm})$ & $74.7 \pm 1.2$ & $82.5 \pm 1.8$ & $90.8 \pm 1.3$ & $102.0 \pm 2.7$ & $106.6 \pm 1.6$ & $114.8 \pm 1.9$ \\
\hline Weight (kg) & $10.2 \pm 0.6$ & $11.4 \pm 0.6$ & $13.2 \pm 0.4$ & $16.8 \pm 1.3$ & $16.9 \pm 0.5$ & $20.6 \pm 0.7$ \\
\hline BMI $\left(\mathrm{kg} / \mathrm{m}^{2}\right)$ & $18.3 \pm 0.8$ & $16.8 \pm 0.5$ & $15.9 \pm 0.3$ & $16.0 \pm 0.5$ & $14.9 \pm 0.3$ & $15.6 \pm 0.7$ \\
\hline BMI Z-score & $0.5 \pm 0.5$ & $0.1 \pm 0.4$ & $-0.1 \pm 0.2$ & $0.3 \pm 0.4$ & $-0.4 \pm 0.3$ & $0.2 \pm 0.2$ \\
\hline \multicolumn{7}{|c|}{ Stimulated LH (IU/L) } \\
\hline Median & 7.57 & 4.86 & 4.31 & 2.19 & 3.74 & 2.61 \\
\hline Minimum & 5.63 & 2.38 & 2.84 & 1.15 & 1.63 & 0.87 \\
\hline Maximum & 7.66 & 8.00 & 9.96 & 3.92 & 5.47 & 3.46 \\
\hline \multicolumn{7}{|c|}{ Stimulated FSH (IU/L) } \\
\hline Median & 26.56 & 20.51 & 20.14 & 12.15 & 17.22 & 11.53 \\
\hline Minimum & 22.82 & 16.62 & 9.11 & 7.94 & 10.40 & 6.81 \\
\hline Maximum & 40.39 & 29.43 & 36.15 & 19.00 & 20.69 & 26.95 \\
\hline \multicolumn{7}{|c|}{ Stimulated LH/FSH ratio } \\
\hline Median & 0.21 & 0.25 & 0.21 & 0.16 & 0.26 & 0.19 \\
\hline Minimum & 0.19 & 0.11 & 0.14 & 0.06 & 0.09 & 0.07 \\
\hline Maximum & 0.33 & 0.29 & 0.37 & 0.37 & 0.43 & 0.39 \\
\hline
\end{tabular}


Serum LH concentrations increased in all participants in response to the GnRH injection to a mean level of $3.89 \pm 3.93$ (range, 0.87-9.96) IU/L (Fig. 1A). The GnRH-stimulated LH responses were $5.20 \pm 3.96$ and $2.88 \pm 2.47 \mathrm{IU} / \mathrm{L}$ in girls $0.8-3$ and $3-6$ years $(P<0.001)$ respectively (Fig. 2A). The basal LH did not predict the peak LH concentration. This corresponds to upper cut-off limits of 9.2 IU/L ( $<3$ years) and 5.3 IU/L (3-6 years) for LH. The stimulated LH response correlated inversely with age, $r=-0.59(P<0.001)$. The LH responses in the different age groups are listed in Table 1.

Baseline FSH was 2.00 (range 0.59-10.93) IU/L and increased in all participants in response to the $\mathrm{GnRH}$ injection to a mean level of $18.34 \pm 15.75$ (range 6.8140.39) IU/L (Fig. 1B). The GnRH-stimulated FSH responses were $23.30 \pm 16.17$ and $14.49 \pm 10.30 \mathrm{IU} / \mathrm{L}$ in girls aged 0-3 and 3-6 years respectively (Fig. 2B). The stimulated FSH response correlated inversely with age, $r=-0.53$
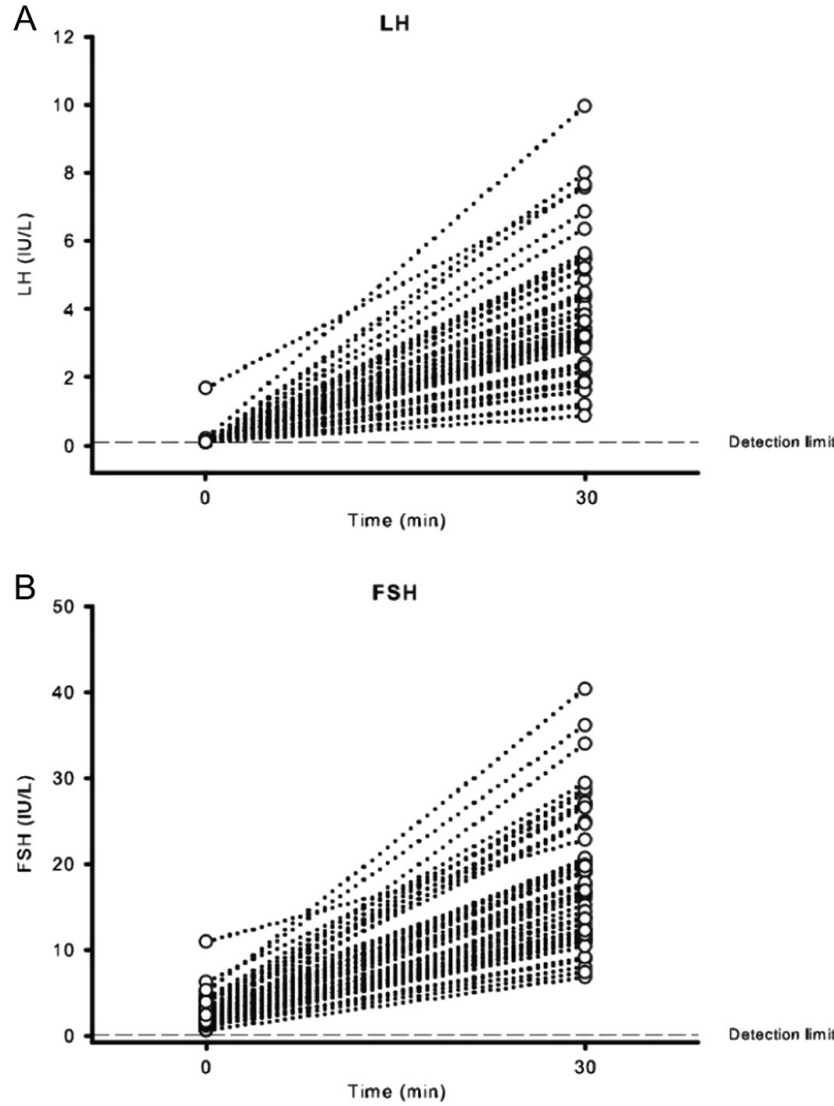

Detection limit

\section{Figure 1}

The figure depicts the serum levels of LH (A) and FSH (B) at baseline (time 0 ) and 30 min after an IV injection of a gonadotropin agonist (Gonadorelin).
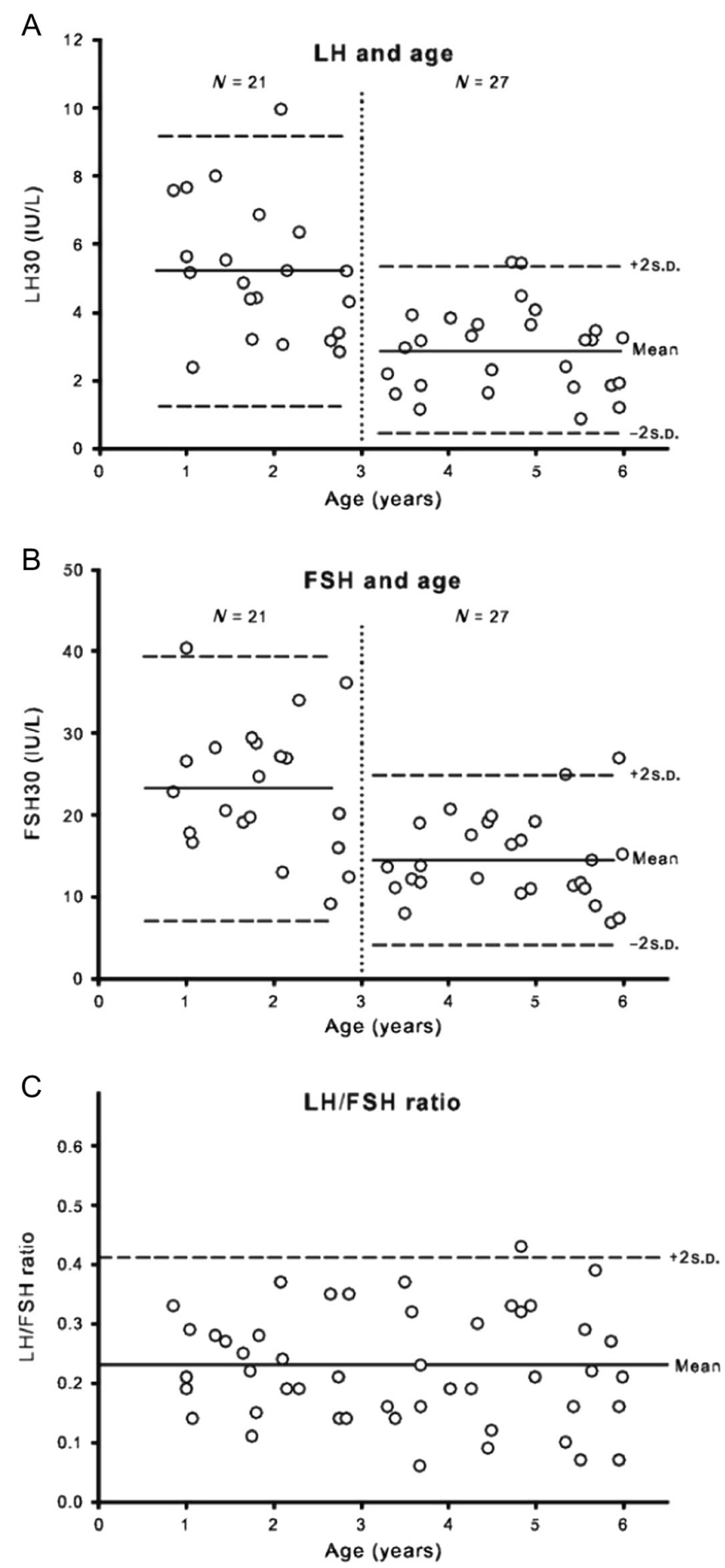

Figure 2

The figure depicts the serum levels of $\mathrm{LH}(\mathrm{A}), \mathrm{FSH}(\mathrm{B})$ and LH/FSH ratio (C) and age 30 min after an IV injection of a gonadotropin agonist (Gonadorelin). Solid lines represent mean concentrations in the age groups $0-3$ and 3-6 years ( $A$ and $B$ ) and the entire cohort (C), and dashed lines represent 2 s.D. The LH/FSH ratio did not exceed 0.43 in any subject (dashed line). 
$(P<0.001)$. The FSH responses in the different age groups are listed in Table 1.

\section{LH/FSH ratio}

The gonadotropin-stimulated LH/FSH ratio was $0.23 \pm 0.19$ (range 0.06-0.43) in the entire cohort and did not vary with age, $r=-0.08, P=0.58$ (Fig. 2C). The LH/FSH responses of the GnRH test in the different age groups are listed in Table 1.

\section{Discussion}

The present study is the first clinical study to investigate the physiological LH, FSH and LH/FSH response to a GnRH test in healthy normal-weight girls below 6 years of age with no history or clinical signs of precocious puberty. Our data demonstrated an age-dependent response to the GnRH test with larger LH and FSH responses in girls aged from 10 months to 3 years compared to girls aged from 3 to 6 years. The LH/FSH ratio was, however, not dependent on age and did not in any single girl of our cohort exceed 0.43. Our data demonstrated that the $\mathrm{LH}$ response to the GnRH test did not normally exceed 9.2 and $5.3 \mathrm{IU} / \mathrm{L}$ in girls aged 10 months to 3 years and 3-6 years respectively. These findings have important implications for diagnosis of central precocious puberty below age 6 years.

The diagnostic work-up for a girl suspected for PP includes a detailed medical history, a thorough clinical examination, laboratory assessments of systemic levels of estrogen, LH, FSH, TSH, SHBG and inhibin B, bone age measurement, ultrasonographic examination of the internal genitals, and occasionally, a brain MRI especially in girls aged less than 6 years with biochemical evidence of central PP (18), i.e. a diagnostic GnRH test, which is the gold standard to detect an activation of the HPG axis (3, $7)$. The number of girls referred for precocious puberty and premature thelarche is increasing $(1,11,19,20)$, making it more important than ever to have normal reference intervals for the different diagnostic tests. To this end, pediatric endocrinologists require a reference interval for the GnRH test for healthy girls aged below 6 years. Establishing a reference interval for the GnRH test increases the diagnostic precision of the test and is important for the clinician to initiate the appropriate treatment for CPP and monitor the treatment effect (21). Until now it has been proposed that it is not feasible to establish a reference interval for the GnRH test (13) and only sparse data covering a large age range for the GnRH test were available for girls. The normal response to the GnRH test in healthy girls below age 6 years has largely been ignored or extrapolated from the LH response in older girls, which may have caused healthy girls to be erroneously treated for CPP. The lack of reports on the normal response to the GnRH test in girls aged below 6 years precludes us from a direct comparison and discussion of our data with existing literature. In one study, Resende et al. reported the $\mathrm{LH}$ and $\mathrm{FSH}$ responses to a GnRH test for 10 prepubescent girls aged 2.7-10.0 years; LH increased to a maximum of 3.3 (immunochemiluminometry assay, ICMA) or 4.2 (immunofluorometry assay, IFMA) IU/L and FSH to a maximum of 23.7 (ICMA) or 27.1 IU/L (IFMA) (7). Brito et al. investigated the GnRH response in 11 prepubescent girls aged 4.0-10.0 years and recorded an increase in $\mathrm{LH}$ to $3.2 \pm 1.9(1.0-6.9) \mathrm{IU} / \mathrm{L}$ and in $\mathrm{FSH}$ to $16.0 \pm 6.1$ (6.7-24.5) IU/L (IFMA, Delfia) (22). The populations of Resende et al. and Brito et al. were both South American populations. Neely included 8 North American girls in Tanner stage I comprising an older age range (aged 6.6-9.8 years) and recorded an increase in $\mathrm{LH}$ and FSH to $2.0 \pm 1.5$ and $21 \pm 5.5 \mathrm{IU} / \mathrm{L}$ respectively, to a GnRH test (23). The study by Neely et al. (23) demonstrated that the $\mathrm{LH}$ response to the GnRH test decreased with age (until puberty) underscoring the importance to establish a reference interval in girls below 6 years of age. The present study confirmed an inverse association between age and the gonadotropin response in girls aged below 6 years, but the mechanism linking age with the gonadotropin response remains to be investigated. Minipuberty is usually considered to affect girls up to 6 months of age (24), but prolonged periods of minipuberty may exist (25) and could in the youngest girls be the underlying physiological condition accounting for the relationship between age and the gonadotropin response. Until now, no data existed on the physiological response to the GnRH test in girls aged below 3 years, and it remained to be examined if the relative high $\mathrm{LH}$ responses to $\mathrm{GnRH}$ tests in girls with premature thelarche in this age group $(11,13,26)$ were a normal physiological or a pathological response. Now, our data reveal that girls below 3 years of age have a larger physiological LH response to the GnRH test than do older girls.

It was previously reported that the LH/FSH ratio in girls aged $2.5 \pm 0.9$ years with isolated breast development, and no signs of progression to CPP, was $0.29 \pm 0.10$, range 0.11-0.43 (26), which complies entirely with our data. In a Korean study comprising girls with CPP, a 30-min stimulated $\mathrm{LH} / \mathrm{FSH}$ ratio $>0.5$ had a diagnostic sensitivity of $76.6 \%$ and a specificity of $97.4 \%$ for central puberty, but 
ratios as low as 0.23 (10) were also recorded. The study by Kim et al. (10) was not designed to investigate the LH/FSH ratio cut-off for healthy girls, but, rather, it reported the LH/FSH ratio in girls with established CPP. The reported LH/FSH ratio in the study by Kim et al. (10) emphasizes, however, that a cut-off LH/FSH ratio of 0.43 as suggested by our study, does not rule out CPP. As such, the criteria for diagnosing CPP remain to be based on clinical signs, biochemistry, imaging and different diagnostic tests. We also suggest that the biochemical assays for LH and FSH should be based on the same analytical principle, as data from ICMAs and IFMAs differ slightly (7). A LH response to the GnRH test should not trigger treatment for CPP if no other clinical indicators of CPP are present in girls aged below 3 years (13).

It has previously been suggested that basal LH concentrations $>0.1 \mathrm{IU} / \mathrm{L}$ (26) or $>0.3 \mathrm{IU} / \mathrm{L}$ (27) are diagnostic for CPP. Three girls in our study showed increased basal LH concentrations, demonstrating that the predictive value of random LH levels is particularly problematic in girls $<3$ years of age, and this underscores that the GnRH test is, among other criteria, indispensable to confirm CPP. The reason why three girls in our study presented with elevated basal LH could in one case be explained by sustained minipuberty (age 0.80 years), but is of unknown origin in the remaining two cases, where minipuberty cannot explain the elevated LH levels. It is, however, not uncommon to detect high basal LH levels in children younger than ages 2-3 years (3). Follow-up of these girls with elevated basal LH revealed that none of them had progressed to precocious puberty.

The strength of our study is that it was designed with the primary aim to investigate the LH and FSH response to the GnRH test in healthy girls below 6 years of age. It is, however, difficult to recruit a large number of healthy volunteering girls in this age range, and although we succeeded to include 48 participants, it is a limitation to the statistical interpretation of our data, that we did not include a much larger cohort. Moreover, the prepubescent response to the GnRH test is sex specific $(23,28)$, which precludes our data to be extrapolated and used as a reference range for boys suspected for precocious puberty. Whether the LH and FSH response to the GnRH test also depends on ethnicity remains to be investigated.

\section{Conclusion}

In conclusion, this study provides important data on the normal FSH and LH response to a GnRH test in young prepubertal girls and demonstrates that the stimulated LH/FSH ratio does not exceed 0.43 in healthy girls below age 6 years.

Declaration of interest

The authors declare that there is no conflict of interest that could be perceived as prejudicing the impartiality of this study.

\section{Funding}

This study was supported by grants from Aarhus University, the AP Møller Foundation, the Søster og Verner Lipperts Foundation and the Grosserer L.F. Foghts Foundation.

\section{Author contribution statement}

Esben T Vestergaard: Wrote protocol, screened patients, performed the clinical study, collected data, analyzed data, interpreted results, wrote first manuscript draft, edited and revised manuscript, created figures and table, literature research and approved the final manuscript. Mia E Schjørring: Screened patients, performed the clinical study, collected data, interpreted results, edited and revised manuscript and approved the final manuscript. Konstantinos Kamperis: Wrote protocol, screened patients, performed the clinical study, interpreted results, edited and revised manuscript, literature research and approved the final manuscript. Karin Kastberg Petersen: Performed the clinical study, collected data, analyzed data, interpreted results, edited and revised manuscript and approved the final manuscript. Søren Rittig: Wrote protocol, screened patients, performed the clinical study, collected data, interpreted results, edited and revised manuscript and approved the final manuscript. Anders Juul: Collected data, analyzed data, interpreted results, edited and revised manuscript, created figures and table, literature research and approved the final manuscript. Kurt Kristensen: Screened patients, performed the clinical study, collected data, interpreted results, edited and revised manuscript and approved the final manuscript. Niels $\mathrm{H}$ Birkebæk: Wrote protocol, screened patients, performed the clinical study, collected data, analyzed data, interpreted results, edited and revised manuscript, created figures and table, literature research and approved the final manuscript.

\section{Acknowledgements}

$\mathrm{J} \mathrm{H}$ Knudsen is acknowledged for excellent technical assistance.

\section{References}

1 Aksglaede L, Sorensen K, Petersen JH, Skakkebaek NE \& Juul A. Recent decline in age at breast development: the Copenhagen Puberty Study. Pediatrics 2009123 932-939. (doi:10.1542/ peds.2008-2491)

2 Herman-Giddens ME, Slora EJ, Wasserman RC, Bourdony CJ, Bhapkar MV, Koch GG \& Hasemeier CM. Secondary sexual characteristics and menses in young girls seen in office practice: a study from the pediatric research in office settings network. Pediatrics 199799 505-512. (doi:10.1542/peds.99.4.505)

3 Carel J-C \& Léger J. Precocious puberty. New England Journal of Medicine 2008358 2366-2377. (doi:10.1056/NEJMcp0800459)

4 Atay Z, Yesilkaya E, Erdeve SS, Turan S, Akin L, Eren E, Doger E, Aycan Z, Abali ZY, Akinci A et al. The etiology and clinical features of nonCAH gonadotropin-independent precocious puberty: a multicenter study. Journal of Endocrinology and Metabolism 2016101 1980-1988. (doi:10.1210/jc.2015-3500) 
5 Kaplowitz P. Clinical characteristics of 104 children referred for evaluation of precocious puberty. Journal of Endocrinology and Metabolism 200489 3644-3650. (doi:10.1210/jc.2003-031532)

6 Palmert MR, Malin HV \& Boepple PA. Unsustained or slowly progressive puberty in young girls: initial presentation and longterm follow-up of 20 untreated patients. Journal of Endocrinology and Metabolism 199984 415-423. (doi:10.1210/jcem.84.2.5430)

7 Resende EAMR, Lara BHJ, Reis JD, Ferreira BP, Pereira GA \& Borges MF. Assessment of basal and gonadotropin-releasing hormonestimulated gonadotropins by immunochemiluminometric and immunofluorometric assays in normal children. Journal of Endocrinology and Metabolism 200792 1424-1429. (doi:10.1210/jc.2006-1569)

8 Carel JC, Eugster EA, Rogol A, Ghizzoni L, Palmert MR \& Antoniazzi F. Consensus statement on the use of gonadotropin-releasing hormone analogs in children. Pediatrics 2009123 752-762. (doi:10.1542/ peds.2008-1783)

9 Houk C, Kunselman A \& Lee P. The diagnostic value of a brief GnRH analogue stimulation test in girls with central precocious puberty: a single 30-minute post-stimulation LH sample is adequate. Journal of Pediatric Endocrinology and Metabolism 200821 1113-1118.

10 Kim HK, Kee SJ, Seo JY, Yang EM, Chae HJ \& Kim CJ. Gonadotropinreleasing hormone stimulation test for precocious puberty. Korean Journal of Laboratory Medicine 201131 244-249. (doi:10.3343/ kjlm.2011.31.4.244)

11 Sømod ME, Vestergaard ET, Kristensen K \& Birkebæk NH. Increasing incidence of premature thelarche in the Central Region of Denmark - challenges in differentiating girls less than 7 years of age with premature thelarche from girls with precocious puberty in real-life practice. International Journal of Pediatric Endocrinology 20162016 1-8. (doi:10.1186/s13633-016-0022-x)

12 de Vries L, Guz-Mark A, Lazar L, Reches A \& Phillip M. Premature thelarche: age at presentation affects clinical course but not clinical characteristics or risk to progress to precocious puberty. Journal of Pediatrics 2010156 466-471. (doi:10.1016/j.jpeds.2009.09.071)

13 Bizzarri C, Spadoni GL, Botarro G, Montanari G, Giannone G \& Cappa M. The response to gonadotropin releasing hormone (GnRH) stimulation test does not predict the progression to true precocious puberty in girls with onset of premature thelarche in the first three years of life. Journal of Endocrinology and Metabolism 201499 433-439. (doi:10.1210/jc.2013-3292)

14 Marshall WA \& Tanner JM. Variations in pattern of pubertal changes in girls. Archives of Disease in Childhood 196944 291-303. (doi:10.1136/adc.44.235.291)

15 van Rijn RR \& Thodberg HH. Bone age assessment: automated techniques coming of age? Acta Radiologica 201354 1024-1029. (doi:10.1258/ar.2012.120443)

16 Greulich WW \& Pyle SI. Radiographic Atlas of Skeletal Development of the Hand and Wrist, 2nd ed. California, USA: Stanford University Press, 1959.

17 Haycock GB, Schwartz GJ \& Wisotsky DH. Geometric method for measuring body surface area: a height-weight formula validated in infants, children, and adults. Journal of Pediatrics 197893 62-66. (doi:10.1016/S0022-3476(78)80601-5)

18 Kaplowitz PB. Do 6-8 year old girls with central precocious puberty need routine brain imaging? International Journal of Pediatric Endocrinology 20162016 9. (doi:10.1186/s13633-016-0027-5)

19 Teilmann G, Pedersen CB, Jensen TK, Skakkebæk NE \& Juul A. Prevalence and incidence of precocious pubertal development in Denmark: an epidemiologic study based on national registries. Pediatrics 2005116 1323-1328. (doi:10.1542/ peds.2005-0012)

20 Sorensen K, Mouritsen A, Aksglaede L, Hagen CP, Mogensen SS \& Juul A. Recent secular trends in pubertal timing: implications for evaluation and diagnosis of precocious puberty. Hormone Research in Paediatrics 201277 137-145. (doi:10.1159/000336325)

21 Latronico AC, Brito VN \& Carel J-C. Causes, diagnosis, and treatment of central precocious puberty. Lancet Diabetes and Endocrinology 2016 4 265-274. (doi:10.1016/S2213-8587(15)00380-0)

22 Brito VN, Batista MC, Borges MF, Latronico AC, Kohek MBF, Thirone ACP, Jorge BH, Arnhold IJP \& Mendonca BB. Diagnostic value of fluorometric assays in the evaluation of precocious puberty. Journal of Endocrinology and Metabolism 199984 3539-3544. (doi:10.1210/ jc.84.10.3539)

23 Neely EK, Hintz RL, Wilson DM, Lee PA, Gautier T \& Argente J. Normal ranges for immunochemiluminometric gonadotropin assays. Journal of Pediatrics 1995127 40-46. (doi:10.1016/S00223476(95)70254-7)

24 Chellakooty M, Schmidt IM, Haavisto AM, Boisen KA, Damgaard IN, Mau C, Petersen JH, Juul A, Skakkebaek NE \& Main KM. Inhibin $\mathrm{A}$, inhibin B, follicle-stimulating hormone, luteinizing hormone, estradiol, and sex hormone-binding globulin levels in 473 healthy infant girls. Journal of Endocrinology and Metabolism $2003 \mathbf{8 8}$ 3515-3520. (doi:10.1210/jc.2002-021468)

25 Kuiri-Hänninen T, Sankilampi U \& Dunkel L. Activation of the hypothalamic-pituitary-gonadal axis in infancy: minipuberty. Hormone Research in Paediatrics 201482 73-80. (doi:10.1159/000362414)

26 Pescovitz OH, Hench KD, Barnes KM, Loriaux DL \& Cutler GB. Premature thelarche and central precocious puberty: the relationship between clinical presentation and the gonadotropin response to luteinizing hormone-releasing hormone. Journal of Endocrinology and Metabolism 198867 474-479. (doi:10.1210/ jcem-67-3-474)

27 Mogensen SS, Aksglaede L, Mouritsen A, Sorensen K, Main KM, Gideon P \& Juul A. Diagnostic work-up of 449 consecutive girls who were referred to be evaluated for precocious puberty. Journal of Endocrinology and Metabolism 201196 1393-1401. (doi:10.1210/ jc.2010-2745)

28 Oerter KE, Uriarte MM, Rose SR, Barnes KM \& Cutler GB Jr. Gonadotropin secretory dynamics during puberty in normal girls and boys. Journal of Endocrinology and Metabolism 199071 1251-1258. (doi:10.1210/jcem-71-5-1251)

Received 19 January 2017

Revised version received 21 March 2017

Accepted 27 March 2017 